
R. W. Pekala
C. T. Alviso
F. M. Kong
S. S. Hulsey

This Paper Was Prepared Eor Subrittal To ISA 3

Third International Symposium on Aerogels Wurzburg, Germany

September 30 - October 2, 1991

This is a preprint of a paper intended for publication in a journal or proceedings. Since changes may be made before publication, this preprint is made available with the understanding that it will not be cited or reproduced without the permission of the author. 
This document was prepared as an account of work sponsored by an agency of the Uaited States Goverament. Neither the United Stales Government aor the University of California mor any of their employees, makes any warranty, express or implied, or ansumes any legal liability or responsibility for the accuracy. completeness, or usefulmess of auy information, apparatus, product, or process disclosed, or represents that its use would not infringe privately owned rights. Reference herein to any specific commercial products, process, or service by trade mame, trademark, manufacturer, or otherwise does not mecessarily constifure or imply its endorsement, recommendation. or favoring by the Uniled States Government or the University of Califoraia. The views and opinions of authors expressed hereir do not necessarily state or reflect those of the United States Governanent or the University of California, and shall not be used for advertising or product endorsement purposes. 


\title{
AEROGELS DERIVED FROM MULTIFUNCTIONAL ORGANIC MONOMERS
}

\author{
R.W. Pekala, C.T. Alviso, F.M. Kong, and S.S. Hulsey
}

Chemistry \& Materials Science Department

Lawrence Livermore National Laboratory

UCRL-JC- -108602

Livermore, CA 94550 USA

DE92 003060

\begin{abstract}
Traditional inorganic aerogels are made via the hydrolysis and condensation of metal alkoxides. Recently, we reported the synthesis of organic aerogels based upon the aqueous polycondensation of (1) resorcinol with formaldehyde and (2) melamine with formaldehyde. The former materials can also be pyrolyzed in an inert atmosphere to form vitreous carbon aerogels. In both the inorganic and organic systems, the structure and properties of the dried aerogel are dictated by polymerization conditions. Factors such as $\mathrm{pH}$, reactant ratio, and temperature influence the crosslinking chemistry and growth processes taking place prior to gelation. The ability to tailor the structure and properties of aerogels at the nanometer scale opens up exciting possibilities for these novel materials. This paper addresses the chemistry-structure-property relationships of organic aerogels.
\end{abstract}




\section{INTRODUCTION}

Sol-gel polymerizations have largely involved the hydrolysis and condensation of metal alkoxides to form inorganic aerogels or xerogels. Recently, organic modifications of the traditional sol-gel process have led to hybrid materials known as ORMOSIS, ORMOCERS, or CERAMERS [1-3]. In these systems, the reactive components are soluble metal alkoxides and a functionalized oligomer or polymer molecule (e.g. polytetramethylene oxide). Another method for producing inorganic/organic hybrid materials involves swelling a crosslinked polymer network with a metal alkoxide and subsequently carrying out a sol-gel polymerization [4]. Finally, hybrid materials can be formed by the polymerization of a reactive organic monomer (e.g. methyl methacrylate) in an inorganic xerogel [5].

While the above synthetic approaches incorporate organic monomers, oligomers, or polymer molecules into a traditional sol-gel polymerization, our research has focused on extending the sol-gel concept to the polymerization of multifunctional organic monomers, exclusively. The aqueous, polycondensation of (1) resorcinol with formaldehyde and (2) melamine with formaldehyde are proven synthetic routes for the formation of crosslinked gels that can be dried into aerogels or xerogels [6-12]. Furthermore, these organic sol-gel reactions can be modified with inorganic colloids to form new hybrid materials.

The ultrastructure and properties of organic aerogels are analogous to their inorganic counterparts. In general, these materials have continuous porosity, an ultrafine cell/pore size $(\leq 50 \mathrm{~nm})$, high surface area $\left(400-1000 \mathrm{~m}^{2} / \mathrm{g}\right)$, and a solid matrix composed of interconnected colloidal-like particles or polymeric chains with characteristic diameters of $10 \mathrm{~nm}$. This ultrastructure and the low $\mathbf{Z}$ (atomic number) composition are responsible for the unique optical, thermal, electrical, and acoustic properties of organic aerogels. For example, resorcinol-formaldehyde aerogels were recently found to have lower thermal conductivities than silica aerogels [13].

\section{ORGANIC SOL-GEL CHEMISTRY}

The aqueous, polycondensation of 1 mole of resorcinol (1,3 dihydroxybenzene) with 2 moles of formaldehyde proceeds through a sol-gel transition. In this polymerization, resorcinol is a trifunctional monomer capable of adding formaldehyde in the 2-,4-, and/or 6 - ring positions. This monomer along with other di- and tri-hydroxy benzene compounds is particularly reactive because of the electron donating and ortho-, para- directing effects of the attached hydroxyl groups. The substituted rescicinol rings condense with each other to form nanometer-sized clusters in solution. The size of the clusters is regulated by the catalyst concentration (i.e. sodium carbonate) in the resorcinol-formaldehyde mixture. Eventually, the clusters crosslink through their surface groups (e.g. $-\mathrm{CH}_{2} \mathrm{OH}$ ) to form a gel. RF gels and aerogels are dark red in color as a result of oxidation products formed during the polymerization. 
Resorcinol reacts with formaldehyde under alkaline conditions to form mixtures of addition and condensation products. The major reactions include: (1) the formation of hydroxymethyl $\left(-\mathrm{CH}_{2} \mathrm{OH}\right)$ derivatives of resorcinol, (2) the condensation of the hydroxymethyl derivatives to form methylene $\left(-\mathrm{CH}_{2}-\right)$ and methylene ether $\left(-\mathrm{CH}_{2} \mathrm{OCH}_{2}-\right)$ bridged compounds, and (3) the disproportionation of methylene ether bridges to form methylene bridges plus formaldehyde as a byproduct [14,15]. Broad NMR lines are obtained during the early stages of the sol-gel polymerization, indicating that the RF clusters are highly crosslinked. Solid state NMR has permitted identification of the above groups only in the dried aerogels.

The size and number of resorcinol-formaldehyde (RF) clusters generated during the polymerization are controlled by the [Resorcinol]/[Catalyst] (R/C) ratio in a formulation. $\mathrm{R} / \mathrm{C}$ values of 50-300 provide an acceptable range in which transparent gels can be synthesized. Outside of this range, opaque gels or precipitates are usually obtained. In general, solutions containing less than $7 \%$ reactants are cured for 7 days at $95^{\circ} \mathrm{C}$ while more concentrated solutions are cured for 1 day at $50^{\circ} \mathrm{C}$ followed by 3 days at $95^{\circ} \mathrm{C}$.

Crosslinked melamine-formaldehyde aerogels that are both colorless and transparent can be synthesized using two different approaches. In the monomer approach, melamine and formaldehyde are mixed in a 1:3.7 molar ratio and diluted with deionized/distilled water to control the overall reactant concentration. Sodium hydroxide (10-100 millimoles) is used as the base catalyst in the initial part of this polymerization. Because melamine is a crystalline solid with limited water solubility, the above slurry has to be heated for $\sim 15$ minutes at $70^{\circ} \mathrm{C}$ to form a clear solution. The solution is then cooled to $45^{\circ} \mathrm{C}$ and acidified with $\mathrm{HCl}$. To form transparent gels, the $\mathrm{pH}$ of the $\mathrm{MF}$ solution is required to be 1.5-1.8 when measured at room temperature. Outside of this range, opaque or translucent gels are formed.

Melamine is a hexafunctional monomer capable of reaction at each of the amine hydrogens. Under alkaline conditions, formaldehyde adds to the above positions to form hydroxymethyl $\left(-\mathrm{CH}_{2} \mathrm{OH}\right)$ groups. In the second part of the polymerization, the solution is acidified to promote condensation of these intermediates, leading to gel formation. The principal crosslinking reactions include the formation of (1) diamino methylene $\left(-\mathrm{NHCH}_{2} \mathrm{NH}-\right)$ and (2) diamino methylene ether $\left(-\mathrm{NHCH}_{2} \mathrm{OCH}_{2} \mathrm{NH}-\right)$ bridges $[16,17]$.

In the oligomer approach, a low molecular weight melamine-formaldehyde polymer (Resimene 714; Monsanto Chemical Co.) is utilized. Resimene 714 results from the condensation of melamine with formaldehyde followed by partial methoxylation. This oligomer is supplied as an $80 \%$ solution in water. MF gels are formed by diluting Resimene 714 with an appropriate amount of deionized/distilled water and adjusting the $\mathrm{pH}$ with $\mathrm{HCl}$. Transparent gels are obtained between a $\mathrm{pH}$ of 2.0-3.0.

All melamine-formaldehyde solutions develop a blue haze as they are cured ( 2 days at $50^{\circ} \mathrm{C}$ followed by 5 days at $95^{\circ} \mathrm{C}$ ). This phenomenon is associated with Rayleigh 
scattering from MF clusters generated in solution. These clusters contain surface functional groups (e.g. $-\mathrm{CH}_{2} \mathrm{OH}$ ) that eventually crosslink to form a gel. The aggregation and crosslinking processes show a strong $\mathrm{pH}$ dependence. Furthermore, the $\mathrm{pH}$ range for the preparation of transparent gels and aerogels is affected by our synthetic approach (monomer vs. oligomer).

$\mathrm{RF}$ and MF gels are converted into aerogels by supercritical extraction from carbon dioxide. Because water is not miscible with liquid $\mathrm{CO}_{2}$, the aquagels are first exchanged with an organic solvent (e.g. acetone), and then processed inside a temperature-controlled pressure vessel. The critical point of carbon dioxide $\left(\mathrm{T}_{\mathrm{c}}=31^{\circ} \mathrm{C} ; \mathrm{P}_{\mathrm{c}}=7.4 \mathrm{MPa}\right)$ is low enough that no polymer degradation takes place during the drying operation. In the case of RF aerogels, the material can be subsequently pyrolyzed at $1100^{\circ} \mathrm{C}$ in an inert atmosphere to form vitreous carbon aerogels. These aerogels are black and no longer transparent due to the visible absorption properties of the carbon matrix. Table I outlines the family of organic aerogels which is currently available.

\section{STRUCTURE-PROPERTY RELATIONSHIPS}

\section{Resorcinol-formaldehyde}

The [Resorcinol]/[Catalyst] (R/C) ratio is the dominant factor which affects the density, surface area, and mechanical properties of RF aerogels. TEM shows that these aerogels are composed of interconnected colloidal-like particles derived from the clusters formed in solution. Under high catalyst conditions (i.e. $\mathrm{R} / \mathrm{C}=50$ ), the particles have diameters of 3-5 $\mathrm{nm}$ and are joined together with large necks, giving the aerogel a fibrous appearance. Under low catalyst conditions (i.e. $\mathrm{R} / \mathrm{C}=200$ ), the particles have diameters of $11-14 \mathrm{~nm}$ and are connected in a "string of pearls" fashior.

The above aerogels have been described as 'polymeric' and 'colloidal', respectively. Characteristics of the 'polymeric' RF aerogel include substantial shrinkage during supercritical drying, small particle size, high surface area, and a high compressive modulus. In contrast, the 'colloidal' RF aerogels exhibit little shrinkage upon supercritical drying, a relatively large particle size, lower surface area, and weak mechanica: properties. At equivalent densities, 'polymeric' $R F$ aerogels prepared at $R / C=50$ are $\sim 3 X$ stiffer than 'colloidal' $\mathrm{RF}$ aerogels prepared at $\mathrm{R} / \mathrm{C}=200$ [18]. Intuitively, this data can be explained in terms of the better interparticle connections in the 'polymeric' aerogel as compared to the 'colloidal' aerogel.

In order to gain some insight into the interconnections between RF particles, C-13 labeled formaldehyde was introduced into the sol-gel polymerization after "cluster" formation but prior to gelation [19]. Previous titration data showed that cluster formation was completed in a $5 \% \mathrm{RF}$ solution after $\sim 3$ hours of polymerization at $95^{\circ} \mathrm{C}$ [8]. The C13 labeled solutions were prepared at this same concentration and permitted to gel. These 
gels were then processed into aerogels in the usual manner.

The carbon backbone of RF aerogels is complex and yields a cross polarization magic angle spinning (CPMAS) C-13 NMR spectrum of 4 principal and 1 minor peak as shown in Figure 1. The 4 most prominent peaks in the NMR spectrum were used for relaxation measurements, and the concentration of a particular carbon site was determined from peak amplitudes. The measured peaks had chemical shifts of $\sim 150,120,60$, and $20 \mathrm{ppm}$ with respect to tetramethyl silane. These peaks were assigned to aromatic carbons with an - $\mathrm{OH}$ $(150 \mathrm{ppm})$, aromatic carbons ortho to an $-\mathrm{OH}(120 \mathrm{ppm})$, aliphatic carbons adjacent to oxygen $(60 \mathrm{ppm})$, and methylene carbons $(20 \mathrm{ppm})$. Peak intensity ratios comparing the enriched aerogels with unlabeled aerogels indicated that the $60 \mathrm{ppm}$ peak primarily represented surface groups while the 20 ppm peak largely reflected groups buried within the RF particles. This finding was expected since an excess of formaldehyde was available in the late stages of "cluster" formation to react with surface sites, thereby forming hydroxymethyl groups $\left(-\mathrm{CH}_{2} \mathrm{OH}\right)$ that condense into methylene ether $\left(-\mathrm{CH}_{2} \mathrm{OCH}_{2}\right)$ bridges.

Relaxation times $\mathrm{T}_{\mathrm{CH}}$ were measured as a function of contact time for the labeled aerogels. At the molecular level, $\mathrm{T}_{\mathrm{CH}}$ is proportional to the inverse square of the dipolar $\mathrm{C}-\mathrm{H}$ interactions within the aerogel. This dipole-dipole coupling was used to elucidate separate motional environments for carbons having similar chemical shifts. The two $\mathrm{T}_{\mathrm{CH}}$ components for the $60 \mathrm{ppm}$ peak reflect methylene ether bridges, hemiformal groups, and hydroxymethyl groups which are in different environments at the surface of the RF particles. The high $\mathrm{T}_{\mathrm{CH}}$ component represents species which are loosely bonded or freely rotating at the surface, while the low $\mathrm{T}_{\mathrm{CH}}$ component represents species that are highly crosslinked and immobile. A ratio of intensities for the low $\mathrm{T}_{\mathrm{CH}}$ component at $60 \mathrm{ppm}$ to the $150 \mathrm{ppm}$ peak showed that a larger fraction of surface groups were crosslinked in the 'polymeric' RF aerogel synthesized at $\mathrm{R} / \mathrm{C}=50$ as compared to the 'colloidal' RF aerogel synthesized at $R / C=200$. Similar conclusions were drawn from inversion recovery cross polarization measurements. These data provide the first semi-quantitative measurement of interparticle crosslink density in organic aerogels. We believe that this parameter ultimately determines the acoustic, thermal, and mechenical behavior of these aerogels. In future experiments, we plan to investigate methods of improving the interparticle crosslink density while keeping the RF particle size fixed.

Recently, a new vertical replication technique allowed us to image RF aerogels at the molecular level so that differences in 'polymeric' and 'colloidal' aerogels could be visualized [20]. TEM stereoimages of $R F$ aerogels prepared at $R / C=50, R / C=200$, and $\mathrm{R} / \mathrm{C}=300$ were obtained. These data clearly showed that the terms 'polymeric' and 'colloidal', as applied to aerogels, do not simply represent two structural extremes. Instead, a complex mixture of ultrastructural units (e.g. spheroidal beads, ladder-like 
chains) is found in each type of aerogel. The TEM stereoimages also provided direct evidence that the interconnected RF particles were microporous. In support of this observation, SAXS data from Schaefer et al. showed that the RF skeletal density was inversely related to the $\mathrm{R} / \mathrm{C}$ ratio and ranged from 0.7 to $1.2 \mathrm{~g} / \mathrm{cc}$ [21].

\section{Carbon}

The R/C ratio manifests itself in the structure and properties of carbon aerogels. Particle size, density, surface area, and mechanical properties show similar trends to the RF aerogels. The pyrolysis temperature also impacts the composition and microstructure of carbon aerogels. In recent experiments, $\mathrm{RF}$ aerogels were pyrolyzed at temperatures ranging from $600-1100^{\circ} \mathrm{C}$ and their specific surface area was examined. Figure 2 shows that the surface area decreases as the pyrolysis temperature increases, eventually reaching a limiting value for $\mathrm{T} \geq 900^{\circ} \mathrm{C}$. A concomitant increase in the $\mathrm{C}: \mathrm{H}$ ratio was observed.

In general, phenolic-based carbons are not very graphitizable. Raman spectroscopy was used to monitor the structure and order of carbon aerogels as a function of the pyrolysis temperature. Figure 3 compares the Raman spectra for carbon aerogels heat treated at $1050^{\circ} \mathrm{C}$ and $2100^{\circ} \mathrm{C}$. Peaks observed at 1350 and $1580 \mathrm{~cm}^{-1}$ shift were assigned to disordered and ordered carbon phases, respectively [22]. The $\mathrm{I}_{1350} / \mathrm{I}_{1580}$ ratio increases with pyrolysis temperature while the line width decreases substantially. Both samples can be described as glassy carbons with very little order. As such, we have been unable to intercalate carbon aerogels with alkali metals to any large extent.

The electrical and capacitance properties of carbon aerogels are under investigation for applications such as chemical sensors and double layer capacitors. Figure 4 shows that room temperature electrical conductivity increases with aerogel density. The electrical conductivity of the $R / C=100$ samples was consistently higher than the $R / C=200$ samples when compared at similar densities. We believe that differences in particle interconnectivity explain the above data in much the same way that mechanical properties depend upon the $\mathrm{R} / \mathrm{C}$ ratio.

The thermal conductivity of carbon aerogels, as calculated from thermal diffusivity measurements performed at $300^{\circ} \mathrm{C}$, is shown in Figure 5. The thermal conductivity increases with aerogel density in nearly a linear fashion. Although only one data point has been taken for an $R / C=200$ sample, it clearly lies below the line for the $R / C=100$ samples. Differences in interparticle connectivity are thought to be responsible for this result.

\section{Melamine-formaldehyde}

The $\mathrm{pH}$ of a melamine-formaldehyde solution appears to be the most critical parameter controlling the optical clarity of a dried MF aerogel. Using the monomer approach, gels prepared at $\mathrm{pH}=1.7$ resulted in transparent aerogels, whereas gels prepared at $\mathrm{pH}=0.7$ led to opaque aerogels. A comparison of IR absorption peaks and intensity ratios showed that the two aerogels were identical. Solid state NMR measurements also revealed identical 
chemical shifts and relaxation parameters. Based upon these data, solution $\mathrm{pH}$ does not appear to influence the type or degree of crosslinking in the aerogels, rather it affects the aggregation of clusters which ultimately determines pore size and optical clarity.

The oligomer approach is the prefered method for the production of MF aerogels. It enables us to produce aerogels over a wider $\mathrm{pH}$ range, and it simplifies the synthetic prosedure. Figure 6 shows the dependence of specific surface area upon solution $\mathrm{pH}$. MF aerogels have extremely high surface areas ranging from $880-1020 \mathrm{~m}^{2} / \mathrm{g}$ with a maximum value being obtained at $\mathrm{pH}=2.7$. Extinction coefficients have been calculated for these same aerogels in the ultraviolet/visible spectrum. Figure 7 shows that MF aerogels with good transmissive properties are achieved between $\mathrm{pH}=2.0-3.0$. The optical properties of MF aerogels compare favorably with those of the best silica aerogels.

\section{SUMMARY}

Sol-gel polymerizations are not unique to metal alkoxides; in theory, any multifunctional monomer can be polymerized in dilute solution to form an aerogel. Our work has demonstrated that organic-based aerogels can be successfully synthesized from the aqueous polycondensation of (1) resorcinol with formaldehyde and (2) melamine with formaldehyde. The former materials can also be pyrolyzed to give vitreous carbon aerogels.

The catalyst concentration (solution $\mathrm{pH}$ ) is the major variable controlling the structure and properties of organic aerogels. It affects the density, surface area, particle size, and pore size of these materials. This ultrastructure determines the mechanical, acoustic, optical, thermal, and electrical behavior of organic aerogels. In particular, the interparticle crosslink density has a major effect upon these macroscopic properties.

\section{ACKNOWLEDGMENT}

This work was performed under the auspices of the U.S. Department of Energy by the Lawrence Livermore National Laboratory under contract \#W-7405-ENG-48. The authors would like to thank Dr. Bruce Cook (Ames Laboratory) for providing the electrical and thermal conductivity measurements, Dr. Phil Trainer (EG\&G Mound Laboratory) for the Raman data, and Dr. Ray Ward (LLNL) for the NMR data.

\section{REFERENCES}

[1] H. Schmidt and H. Wolter, J. Non-Cryst. Solids 121 (1990) 428.

[ 2] H.H. Huang, B. Orler, and G.L. Wilkes, Macromolecules 20 (1987) 1322.

[3] A.B. Brennan and G.L. Wilkes, Polymer 32(4) (1991) 733.

[4] C.-C. Sun and J.E. Mark, Polymer 30 (1989) 104.

[ 5] E.J.A. Pope, M. Asami, and J.D. Mackenzie, J. Mat. Res. 4(4) (1989) 1018.

[6] R.W. Pekala, J. Mat. Sci. 24 (1989) 3221. 
[7] R.W. Pekala and F.M. Kong, Polym. Prpts. 30(1) (1989) 221.

[8] R.W. Pekala and F.M. Kong, J. de Physique Coll. Suppl., 50(4) (1989) C4-33.

[9] J.D. LeMay, R.W. Hopper, L.W. Hrubesh, and R.W. Pekala, MRS Bulletin 15(12) (1990) 19.

[10] R.W. Pekala, C.T. Alviso, and J.D. LeMay, Proc. 5th Ultrastructure Processing Conf., Orlando (February 18-21, 1991), in press.

[11] C.T. Alviso and R.W. Pekala, Polym. Prpts. 32(3) (1991) 242.

[12] R.W. Pekala and C.T. Alviso, in Better Ceramics Through Chemistry IV, Pittsburgh: Materials Research Society (1990) p. 791.

[13] X. Lu, M.C. Arduini-Schuster, J. Kuhn, O. Nilsson, J. Fricke, and R.W. Pekala, Science, submitted.

[14] D.D. Werstler, Polymer 27 (1986) 757.

[15] A. Sebenik, U. Osredkar, and I. Vizovisek, Polymer 22 (1981) 804.

[16] W.J. Blank, J. Coat. Tech., 51(656) (1979) 61.

[17] I.H. Updegraff, in Encyclopedia of Polymer Science and Engineering, New York: John Wiley \& Sons (1985) p. 752.

[18] R.W. Pekala, C.T. Alviso, and J.D. LeMay, J. Non-Cryst. Solids 125 (1990) 67.

[19] R.W. Pekala and R.L. Ward, Polym. Prpts. 31(1) (1990) 167.

[20] R.W. Pekala, T.M. Tillotson, L.W. Hrubesh, and G.C. Ruben, J. Mat. Sci., in press.

[21] D.W. Schaefer, Sandia National Laboratory, Albuquerque, NM, private communication.

[22] K. Kinoshita, Carbon, New York: John Wiley \& Sons (1988) p. 115. 


\section{FIGURE CAPTIONS}

Figure 1. C-13 CPMAS spectrum of a resorcinol-formaldehyde aerogel obtained at a spinning speed of $4 \mathrm{kHz}$ ( $\mathrm{s}=$ spinning side band, ${ }^{*}=$ measured peak).

Figure 2. BET surface areas (nitrogen adsorption) of carbon aerogels pyrolyzed at various temperatures. All samples were prepared at $10 \%$ reactants with $\mathrm{R} / \mathrm{C}=200$.

Figure 3. Raman spectra for carbon aerogels heat treated at $1050^{\circ} \mathrm{C}$ and $2100^{\circ} \mathrm{C}$.

Figure 4. Electrical conductivity vs. density for carbon aerogels prepared at different R/C ratios. All samples were pyrclyzed at $1050^{\circ} \mathrm{C}$.

Figure 5. Thermal conductivity vs. density for carbon aerogels prepared at different $\mathrm{R} / \mathrm{C}$ ratios. All samples were pyrolyzed at $1050^{\circ} \mathrm{C}$.

Figure 6. BET surface areas (nitrogen adsorption) for melamine-formaldehyde aerogels prepared at different $\mathrm{pHs}$ using the oligomer approach.

Figure 7. UV/VIS extinction coefficients for melamine-formaldehyde aerogels prepared at different $\mathrm{pHs}$ using the oligomer approach. 


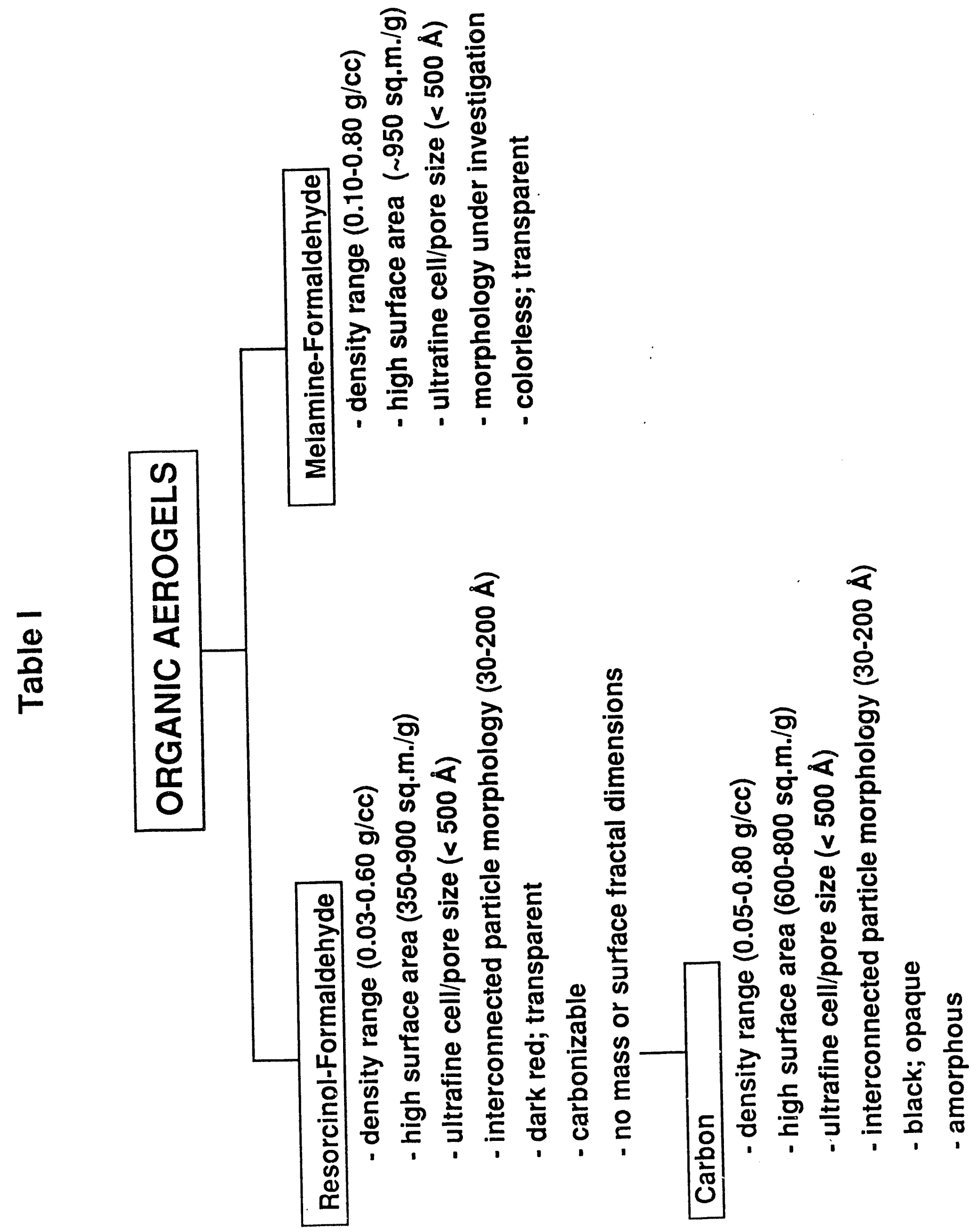




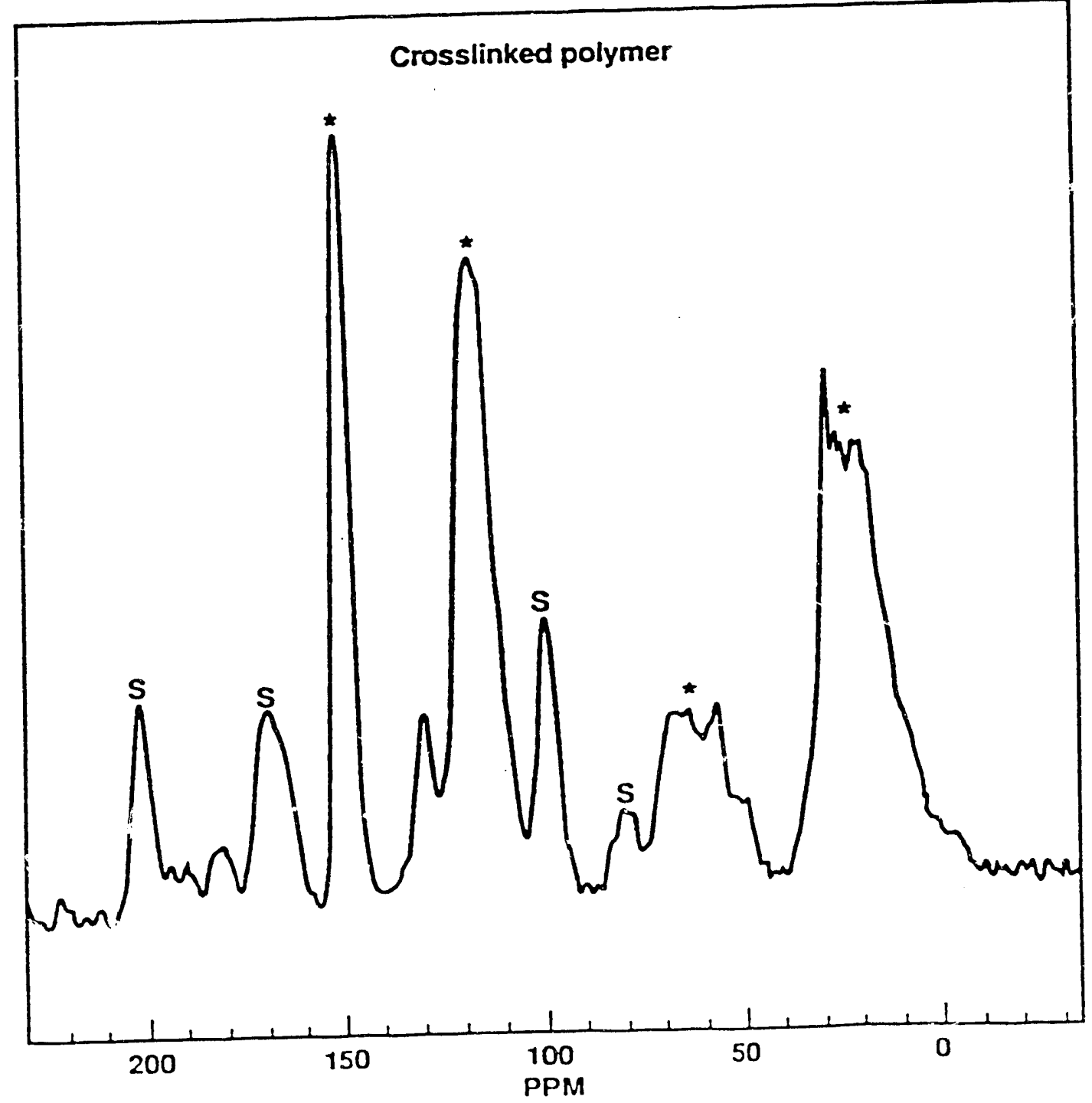




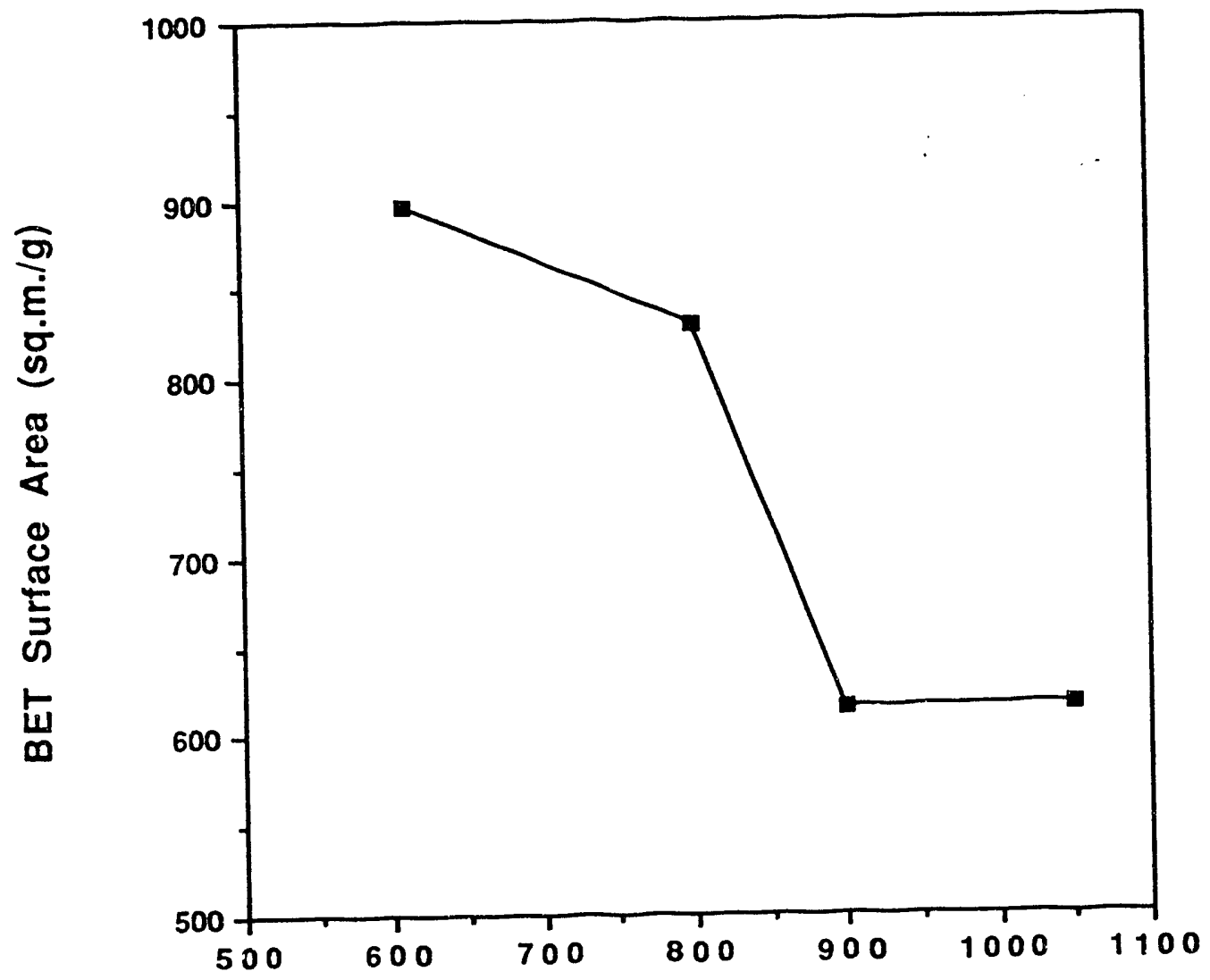

Pyrolysis Temperature $\left({ }^{\circ} \mathrm{C}\right)$ 


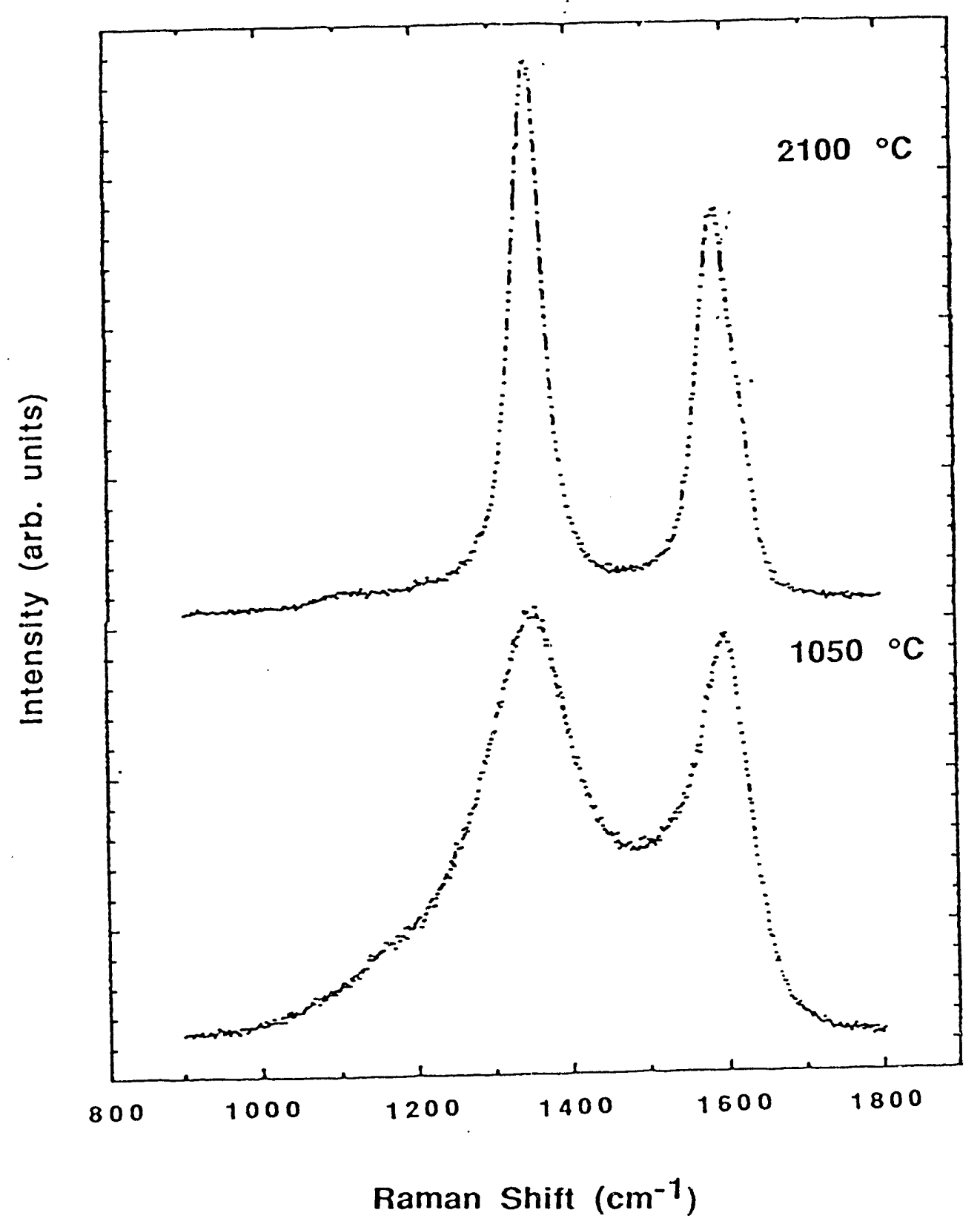




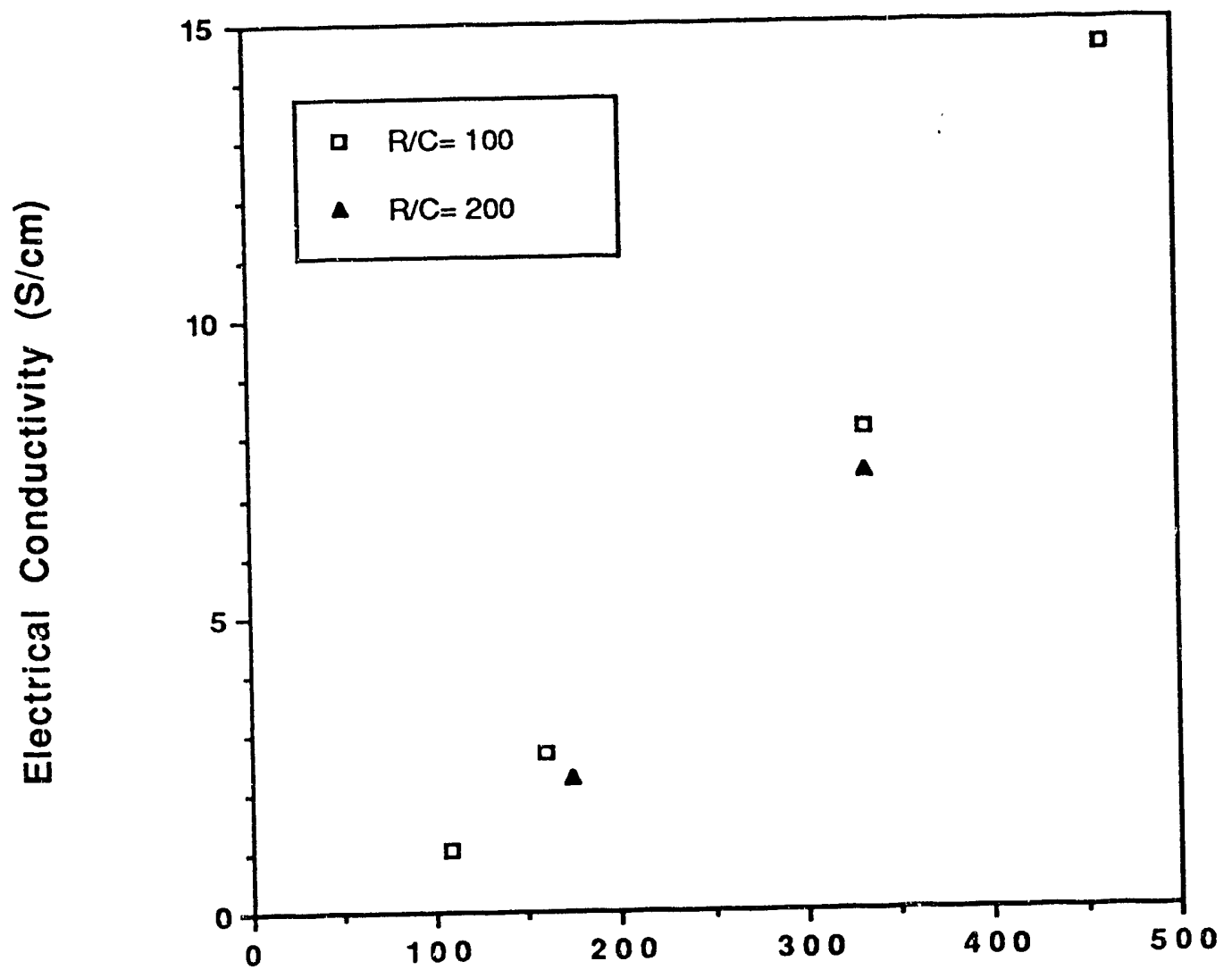

Density (mg/cc) 


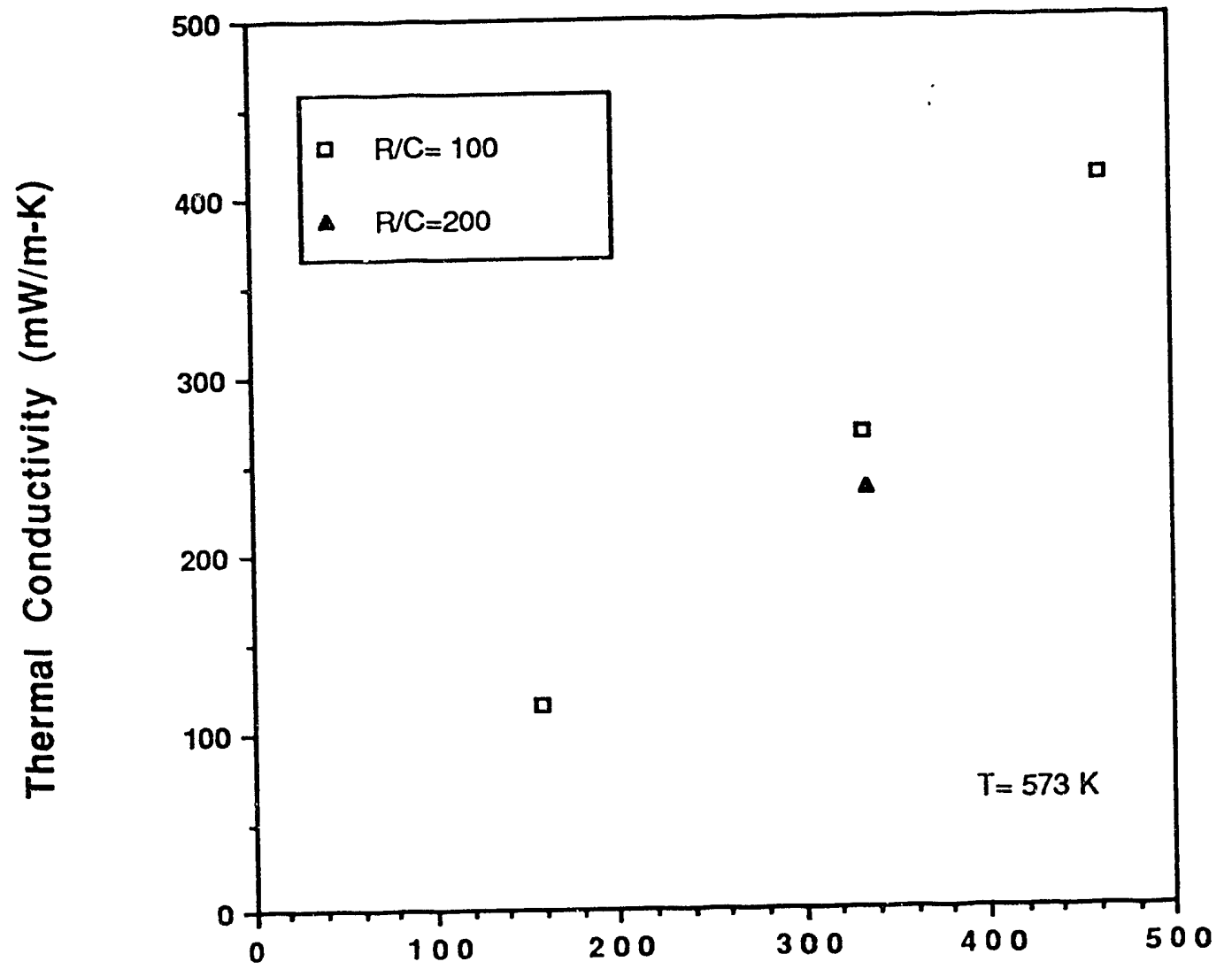

Density (mg/cc) 


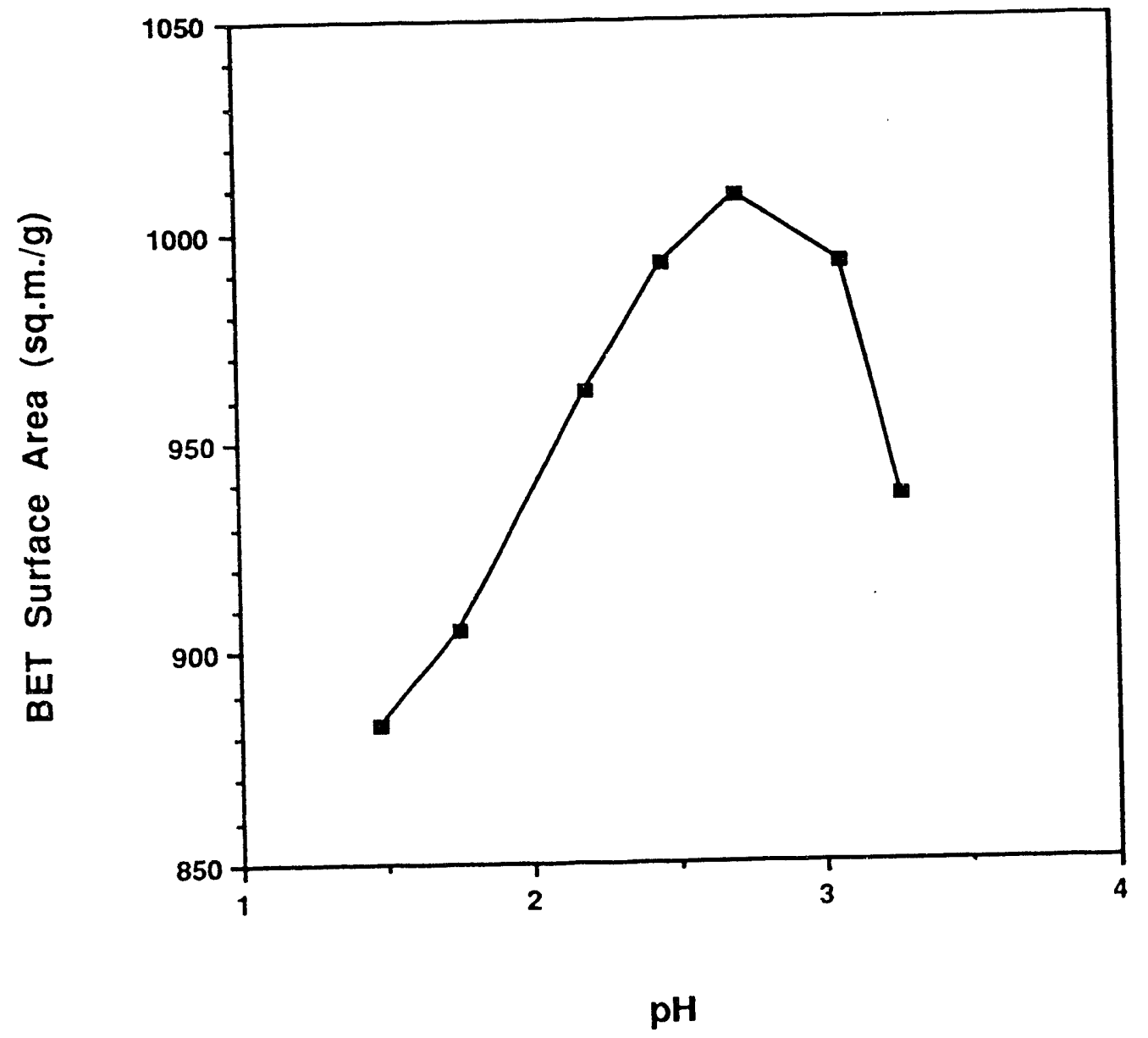




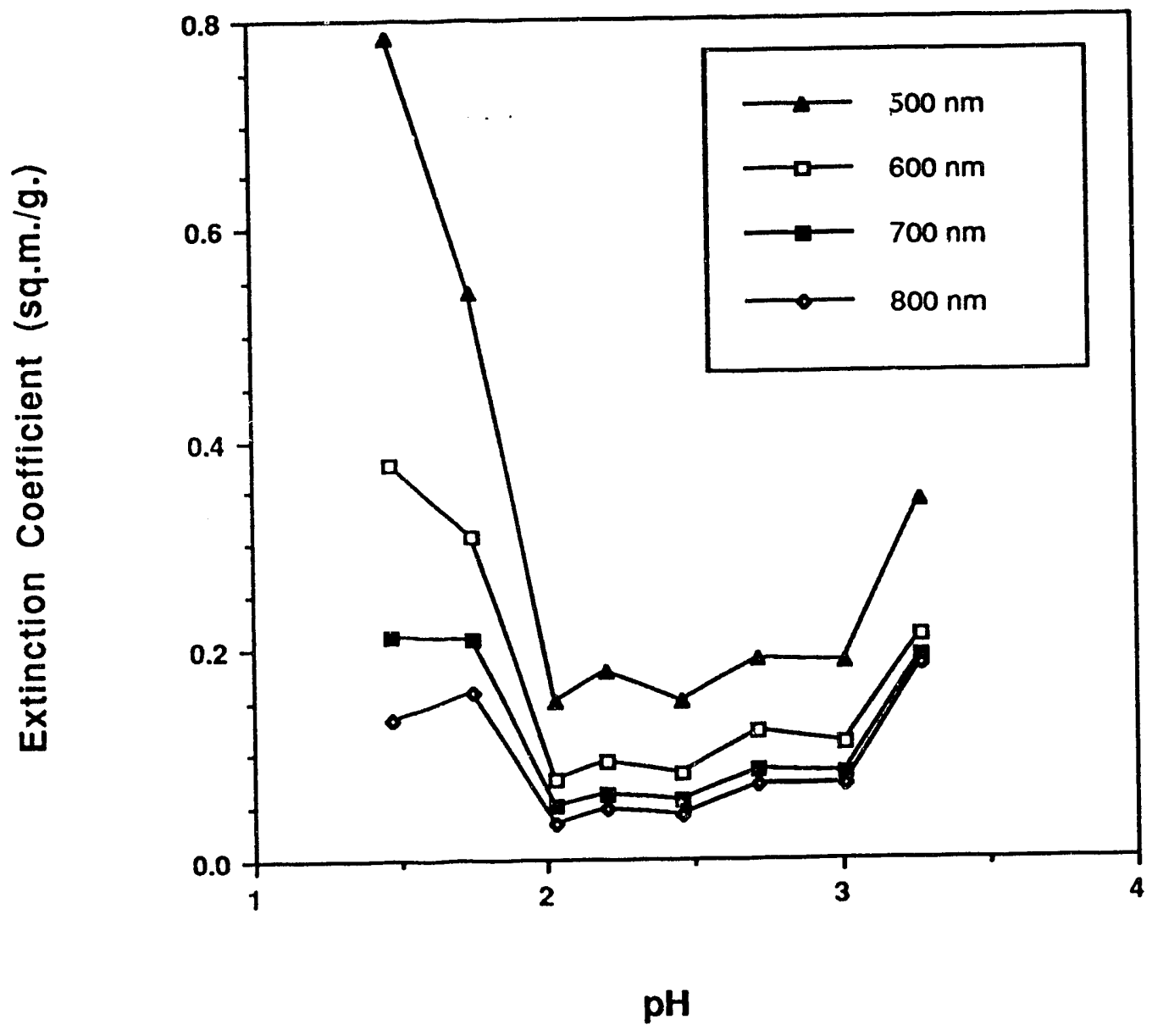



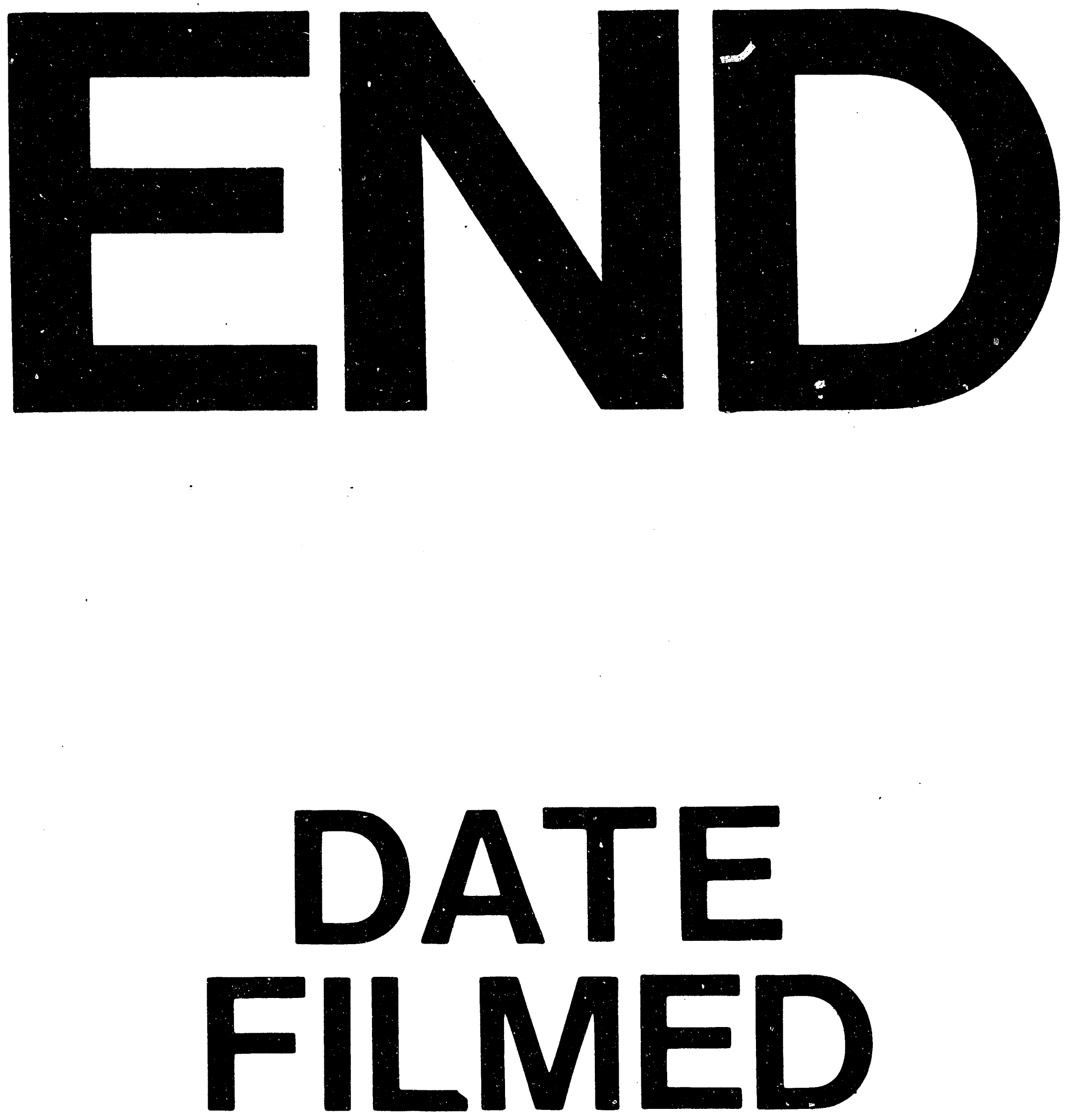

1

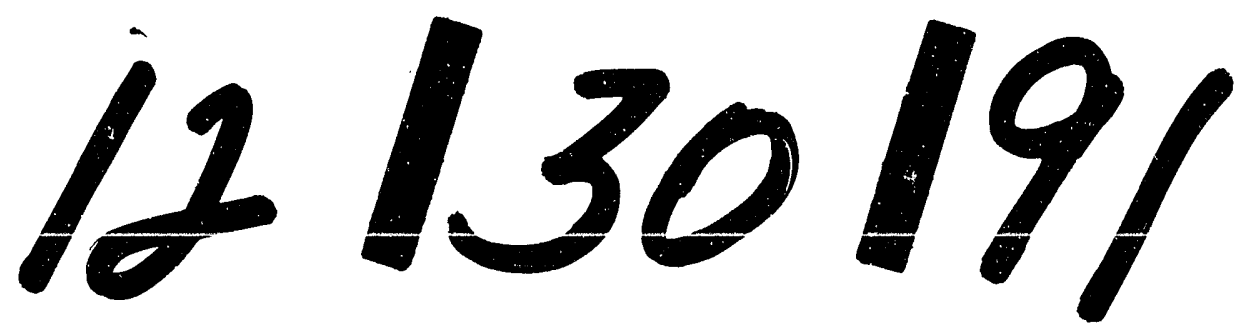


